\title{
IMPACT OF EXTERNAL ACTIONS UPON STRUCTURE OF ALUMINIUM ALLOYS AND COMPOSITES
}

\author{
G.A. Kosnikov ${ }^{1}$, A. S. Eldarkhanov ${ }^{2}$ \\ ${ }^{1}$ Saint- Petersburg State Polytechnical University, St-Petersburg, Russian Federation, \\ ${ }^{2}$ Grozny State Oil Technical University, Grozny, Russian Federation \\ E-mail address: figovsky@gmail.com
} Keywords: silumins, nanocomposites; vibration, ultrasonic, magneto-hydrodynamic (MHD) and
plasma treatment; liquid state, two-phased condition; structure, properties.

\begin{abstract}
Presented are research results of impact of low-frequency vibration, ultrasonic, magneto-hydrodynamic (MHD) and plasma treatment of alloys, in liquid state and two-phase condition, upon structure and properties of silumins and silumin-based nanocomposites.
\end{abstract}

\section{INTRODUCTION}

Nearly in every economically developed country great attention is paid to a problem of development of metal matrix composites. With due consideration of aluminium alloy properties, these are them that are widely used matrix alloys. In the face of a range of unclarified theoretical issues, practical and economic problems which have not been solved yet, those nanocomposites call much attention, in which a dispersed phase (less than $100 \mathrm{~nm}$ ), introduced ex-situ or originated in the melt, resulting from carrying reactions, provides for formation of a unique package of performance properties [1-3]. In-situ reactions, carrying in the alloy, when reactive metals are introduced, gases or chemical compounds, result in strengthening phases, thermodynamicallystable, wetted by the alloy due to coherent boundaries, thermally-stable at higher operating temperatures.

Three process engineering solutions are used to manufacture nanocomposites: powder metallurgy process, impregnation of strengthening pre-manufactured elements and liquid-phase technologies.

These are liquid-phase technologies, associated with strengthening and modifying the premanufactured alloys, with usage of nanoparticles, that are the most common, enabling to produce shaped objects of any complexity of outer configuration and cavities. But the use of these technologies causes a number of specific problems, related to introduction and regular distribution of nanoparticles within the alloy, maintenance of sedimentological stability of metallic suspension in all phases of casting, from raw materials preparation, matrix-assisted alloy melting and processing, in liquid state, introduction of nanoparticles into melt prior to formation of structure and properties in the course of solidification, thermal treatment, usage of waste. At that, the problem of sedimentological stability of cast composites is directly related to both formation of structures and properties and techniques used for casting.

Irrespective of the behavior in the alloy, nanoparticles remain in the casting as isolated inclusions and influence upon the product structural strength, what is more, the influence in no small degree depends on their position relative to structural elements of the matrix-assisted alloy.

These are temperatures of nanoparticles introduction into the melt and product forming that determine any processes, related to behavior of nanoparticles in the alloy. The higher the temperature of the melt is, when nanoparticles are introduced, the easier their stirring carries, the higher mold-filling capacity the suspension has, when being cast into molds, however, the more probable agglomeration of particles is, as well as loss of suspension sedimentological stability. In addition to that, it is required to pay due consideration to the fact that introduction of isolated nanoparticles into the melt is practically impossible, one needs special introduction techniques. The higher suspension viscosity is, during product forming, the more probable maintenance of regular distribution of nanoparticles in the alloy is, and prevention of their agglomeration. 
In the research work conducted authors proceeded from requirement for a packaged approach to uncover impacts of external actions (low-frequency vibration, UT, MHD-action) upon structure of aluminium alloys and aluminum alloy-based composites, in liquid state and two-phase condition, prospects of use of the thixocasting technology for manufacture of nanocomposites-based products. According to subject matters and results obtained, research conducted may be divided into two groups:

1. Research of vibration treatment impact upon the structure of low-melting pattern substances and ultrasonic treatment (UT) impact upon structure of aluminium alloys, which are matrix-assisted, during manufacture of nanocomposites, and used for thixocasting [4-6];

2. Research of nanostructured, composite-based, aluminium-matrix alloys manufacturing processes, using MHD-action and plasma synthesis [7, 8].

\section{Research and discussion of the results}

1. Vibration and UT impact upon alloy structures [4-6]

1.1. To conduct research of vibration treatment impact upon the crystalline structure of alloys, one used pattern substances, nature of crystallization of which is adequate to that of commercial alloys, silumins amongst others. One used camphene and salol which crystallize like metal melt with formation of a dendrite structure and enable to view the solidification process in a transparent reaction vessel. Salol to consolidate in a three-dimensional model, thickness $150 \mathrm{~mm}$, was exposed to vibration, 46-50 Hz frequency and $5 \mathrm{~mm}$ amplitude. At an initial stage of salol cooling, a small layer of the melt consolidates along the perimeter of an ingot (Figure 1,a). When vibration takes place, its layer growth interrupts, and inside the liquid mass a large number of crystallization seeds arises (CS), which grow, break, then new CS appear, upon fragments of dendrites. A part of these crystals go down to casting bottom, another part, as crystals afloat, enlarges continuously (Figure 1, b). With increase of vibration frequency crystalline structure particle size grows.

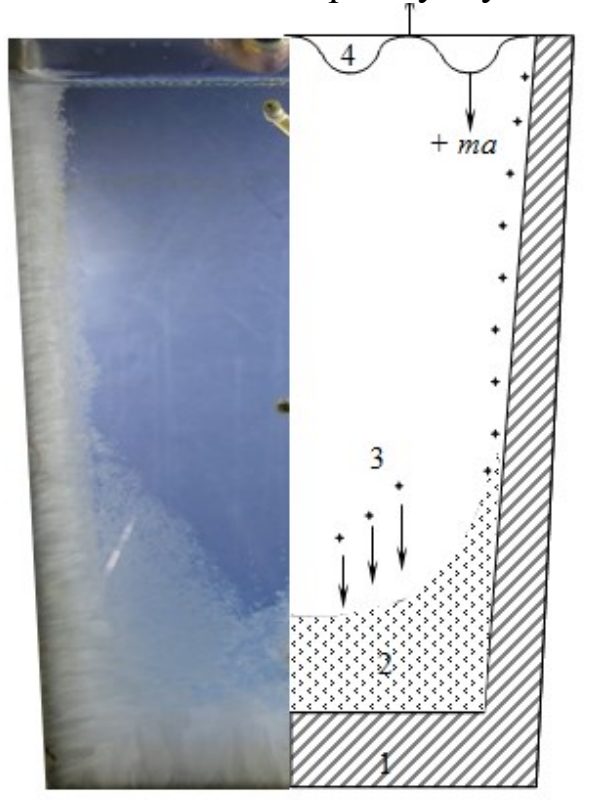

a

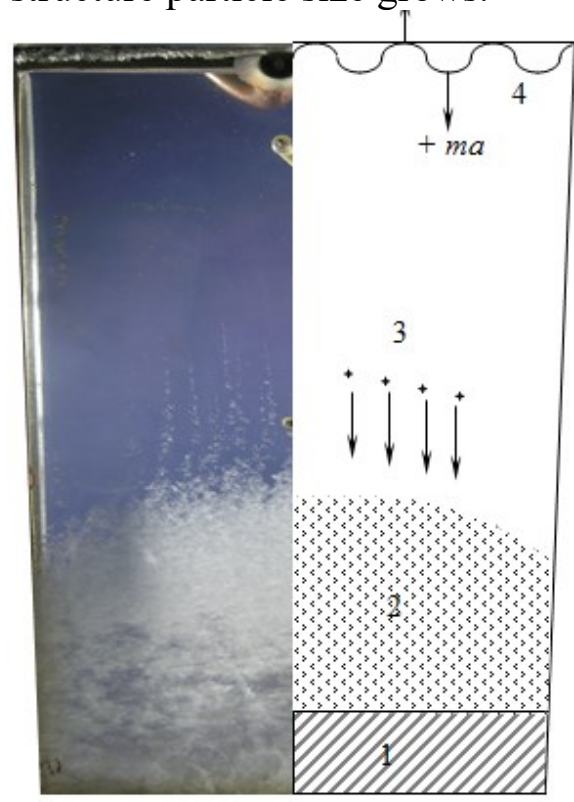

b

Figure 1. Ingot formation models under vibration impact upon solidifying alloy: 1 - solidified skin; 2 - area of crystals settled; 3 - area of cavitational crystal nucleation; 4 - surface wave a - intensive all-sided heat removal;

$\mathrm{b}$ - directed removal of heat from bottom;

During research works it was found that with increase of vibration frequency the melt cooling rate rises sharply and maximum undercooling value decreases, which is probably related to rapid and thorough stirring of the melt and a higher coefficient of thermal transmission from the melt to the reaction vessel wall. 
Essential are data obtained to give evidence of probability of formation of periodic structures within an ingot, depending on processing modes with vertical direction of vibration. There are three types of these structures:

1. Under high-frequency vibrations and high undercooling of the melt, a structure forms, consisting of light (large crystals) and dark (crystals in tens of times smaller in size) strips to be radially distributed from the seed introduction point (Figure 2, a). At that, the distance between the strips can be adjusted by changing processing modes;

2. Under low-frequencies and slight overheat, a coarser crystalline structure forms (Figure 2, b);

3. When exposed to high frequencies with low amplitude, directional growth of crystals stops, the structure takes a chaotic form (Figure 2, c).

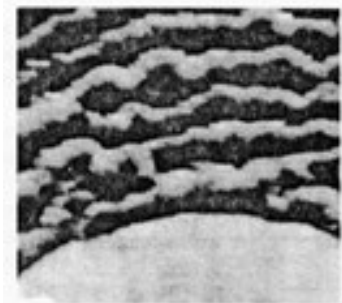

a

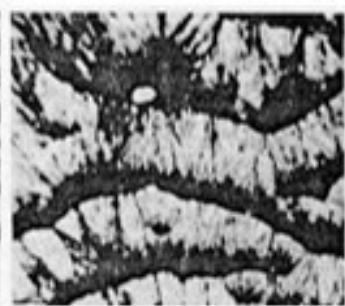

b

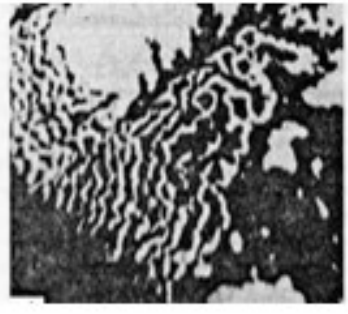

c

Figure. 2. Periodic crystalline structures under optimum (a), below optimum (b) and above optimum (c) vibration frequency values

Revealed trends of formation of periodic structures in alloys, exposed to vibrations, may be used, for instance, if casting of a differentiated structure is required.

It has been found that due to change in direction (vertical, horizontal, horizontal-circumferential), frequencies and amplitudes it becomes possible to control motion trajectories of dispersed particles to be introduced into liquid medium or originating within it. Near-bottom cavity effect is, at that, of paramount importance. The findings give grounds for development of systems of vibrational impact upon alloys during introduction and stirring of disperse particles for manufacture, amongst others, metal matrix composites.

1.2. Structural changes to take place within the melt exposed to UT are in no small agree defined by processes to carry in a two-phase area - nucleation of crystals, their growth, dispersion, mixing processes which, in turn, are related to formation of cavity and acoustic streams within the melt and also depend on crystallization conditions and properties of a material being processed. Degree of cavity development, its nature, intensity of acoustic streams are defined by parameters of ultrasonic field in the melt, properties and volume of the melt processed, presence of impurities, etc.

Whereas there are various grades and compositions of aluminium alloys researched, the most widely used for research of ultrasonic treatment impact are A356 and A357, as well as their closest analog, domestically made AK7 alloy. These alloys also see heavy use in research of thixoformation and formation of aluminium-matrix composites.

To implement thixo-formation processes (thixocasting, rheocasting) of alloys, which have a rather wide range of crystallization intervals, it is obligatory to produce a degenerated (non-dendrite) structure of a solid-state solution, providing for required alloy fluidity in the liquid-solid state, when a mold cavity is filled (molds for pressure thixocasting, dies for thixo-stamping).

Goals of experiments were research of the UT impact upon a dendrite structure of the AK7 alloy solid-state solution, subject to changes to temperature ranges and exposure time, analysis of UT impact upon thermal effects arising and peculiarities of defect formation in an ingot being manufactured. 


\section{Materials, equipment and instruments:}

1. AK7 alloy was delivered from an industrial establishment; the thermal study made it possible to determine alloy critical temperatures: liquidus temperature $\mathrm{TL}=6040 \mathrm{C}$, zero-fluidity temperature $\mathrm{T} 0=5720 \mathrm{C}$, solidus temperature $\mathrm{TS}=5640 \mathrm{C}$.

2. One used an ultrasonic unit within the UZG 3-4M generator, $4 \mathrm{~kW}$ capacity, PMS-15A/18 magnetostrictive converter and sender (wave guide). The wave guide consists of two parts: conical part $\varnothing 65 \times 40 \mathrm{~mm}$, length $155 \mathrm{~mm}$, material: steel 45; and cylindrical part made of VN-2AE $\varnothing 45$ $\mathrm{mm}$, length $90 \mathrm{~mm}$; the conical and cylindrical part are connected by means of a steel stud.

3. The alloy was cast into a graphite-fireclay crucible or stainless steel crucible, diameter $120 \mathrm{~mm}$, height $180 \mathrm{~mm}$. Metallographic specimen were made by means of alloy drawing into a quartz tube, inner diameter $16 \mathrm{~mm}$, and quenching in water.

4. A resistance furnace, with heating temperature up to $950^{\circ} \mathrm{C}$ and XA-thermocouple; induction crucible furnace, capacity $15 \mathrm{~kg}$ (as per steel), with MGP-100 generator (frequency $2500 \mathrm{~Hz}$ ); control and instrumentation facility to measure temperature, connected to a PC to keep records of temperature in the "temperature - time" coordinate system; portable and stationary XA immersion thermocouples with visual temperature control; argon supply system; "Reichartjung.mef3"quantity-related television microscope, with "THIXOMET" software; system of equipment to produce metallographic specimen.

When the melt was exposed to UT, in a two-phase state $\left(580-590^{\circ} \mathrm{C}\right)$, which lasted $5-15$ minutes directly in the area under the wave guide, one could observe gas-shrinkage holes (Figure 3). In that particular area the alloy solidification took place lastly, which led to formation of shrinkage defects in the two-phase area, in which, apparently, hydrogen flowed off.

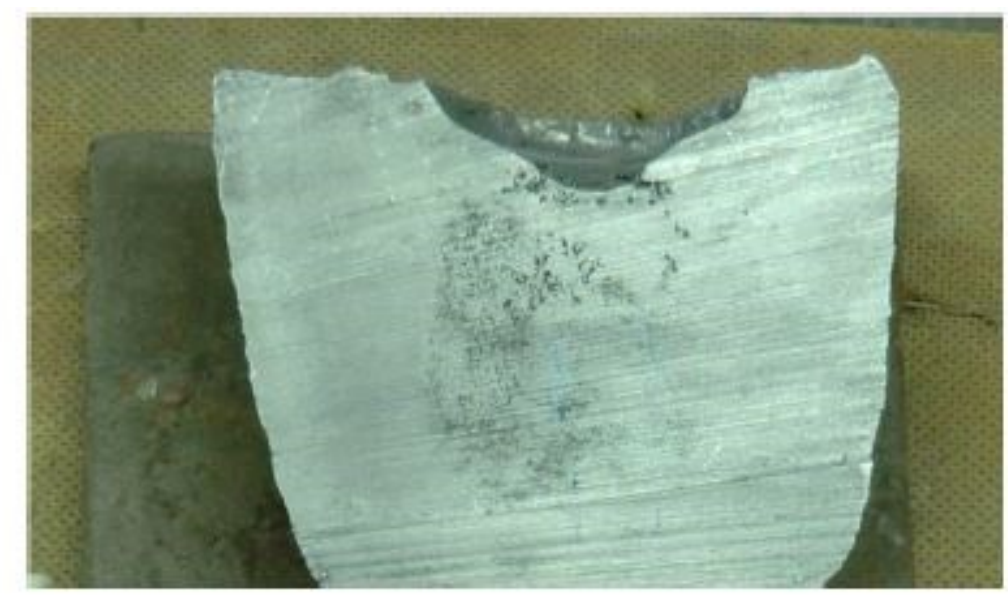

Figure 3. Gas-shrinkage holes in ingot cavity

During the research work one carried out experiments, differing in temperature intervals and UT time.

Experiment 1. Weighted amount of charge, $2 \mathrm{~kg}$, was molten within a resistance furnace, heated to $750^{\circ} \mathrm{C}$; then, a cold wave guide was introduced for a depth of $10 \mathrm{~mm}$. The next step was UT initiation. In 6 minutes temperature fell to a point of $610^{\circ} \mathrm{C}$, and a sample was taken (Figure 4, a). In the 15 th minute the temperature value was $588^{\circ} \mathrm{C}$, UT was deactivated, another samples were taken (Figure 4, b). 


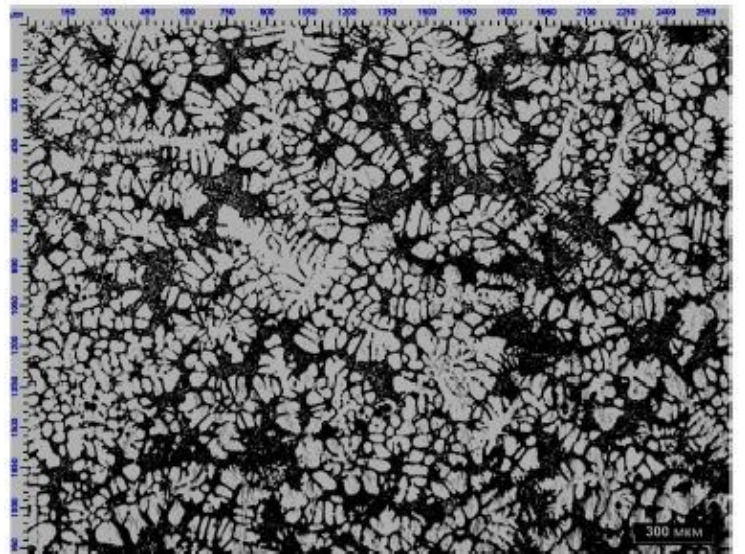

a

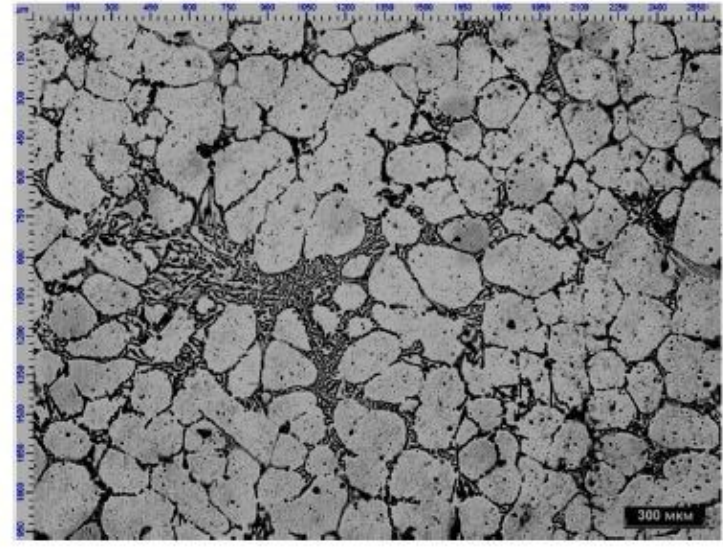

b

Figure 4. Structure of specimen: $\mathrm{a}-\mathrm{UT}$ at temperature above $610^{\circ} \mathrm{C}, 6$ minutes; $\mathrm{b}-\mathrm{UT}$ within 610 $588^{\circ} \mathrm{C}, 15 \mathrm{~min} . \mathrm{X} 20$, etching

The analysis of presented microstructures shows that UT of the alloy within the above-liquidus temperature range had partial effect upon degeneration of the dendrite structure of the solid-state solution, while further UT, mainly within the liquid-solid state interval, contributed to rather complete degeneration of the dendrite structure.

Experiment 2. The experiment goal (its pattern of temperatures is presented in Figure 5) was assessment of UT impact upon thermal effects within the "wave guide - melt - crucible" system, at the beginning of treatment within the above-liquidus overheating range.

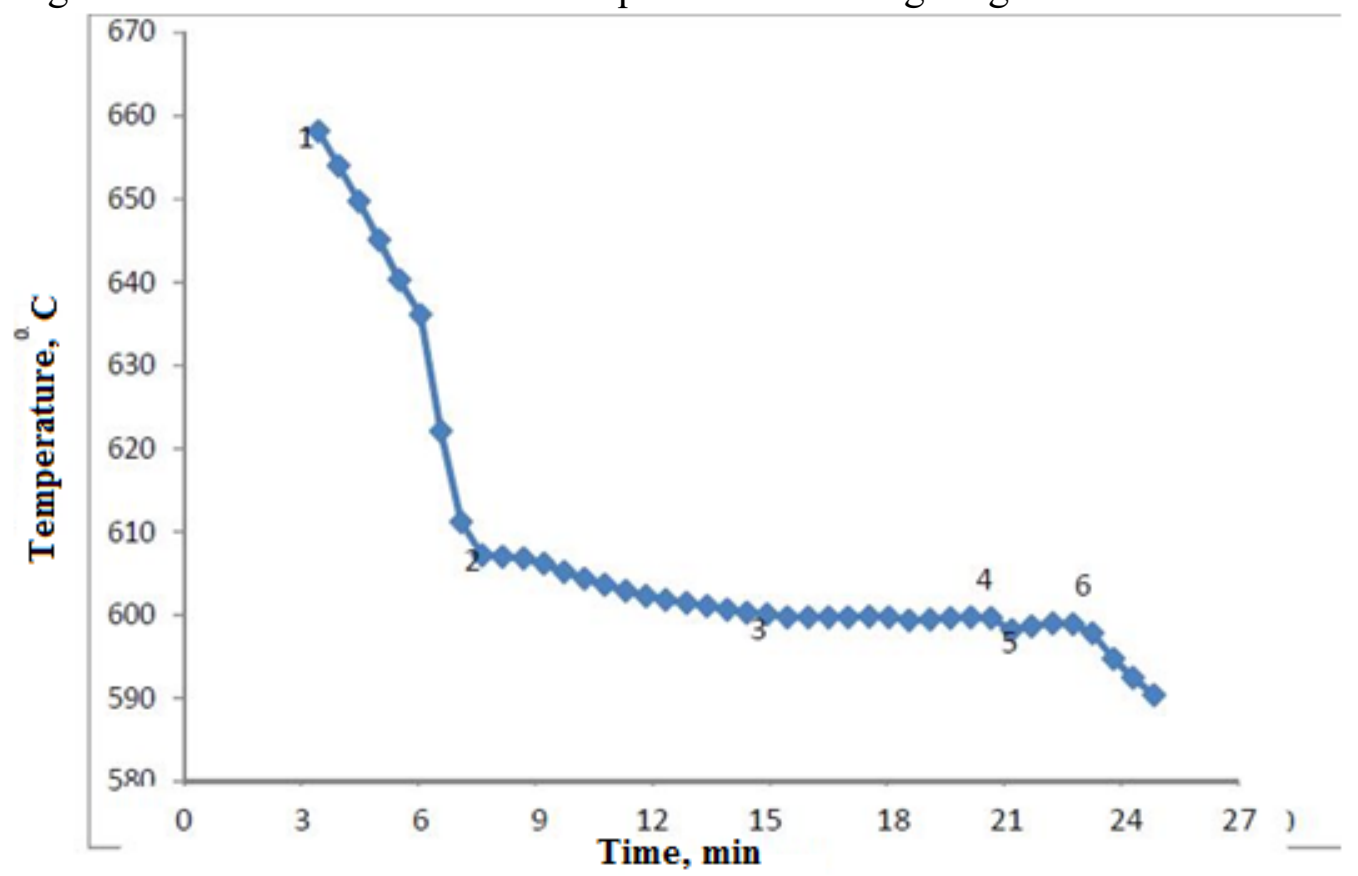

Figure 5. Experiment 2 temperature profile

Weighted amount of charge, $2 \mathrm{~kg}$, was molten within an induction furnace and heated up to $700-$ $720^{\circ} \mathrm{C}$, upon which the melt was recast into a fireclay-graphite crucible, into which one immersed a cold wave guide at a temperature of $658^{\circ} \mathrm{C}$ (Temperature 1). Upon temperature drop to $607^{\circ} \mathrm{C}$ (Temperature 2) UT was activated, a sample was taken to produce specimen. In 6 minutes temperature settled (Temperature 3), then another sample was taken. The melt temperature was the same $\left(600^{\circ} \mathrm{C}\right)$ within 6 minutes (Temperature 4). UT was then deactivated, one more sample was taken, temperature dropped to $598^{\circ} \mathrm{C}$ (Temperature 5). After UT had been activated again, temperature rose to $600^{\circ} \mathrm{C}$ again (Temperature 6), at which UT was stopped. In Figure 6 microstructures of samples were presented which correspond to Temperature 2 and 3. 


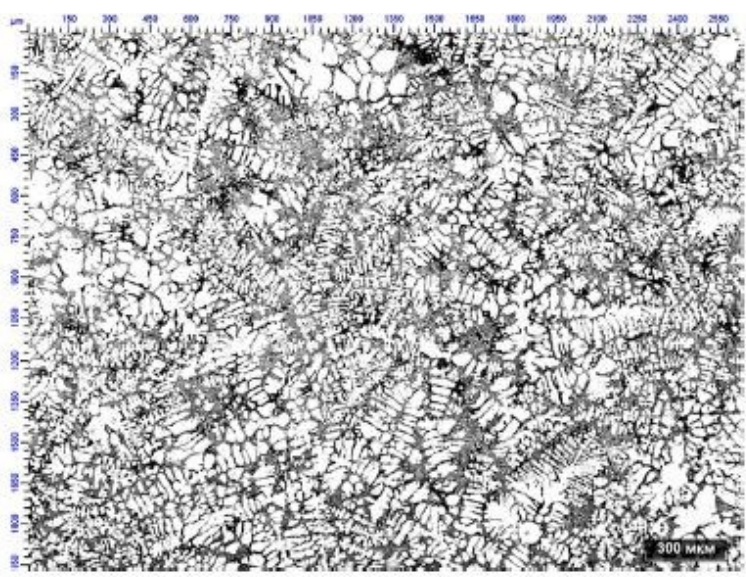

a

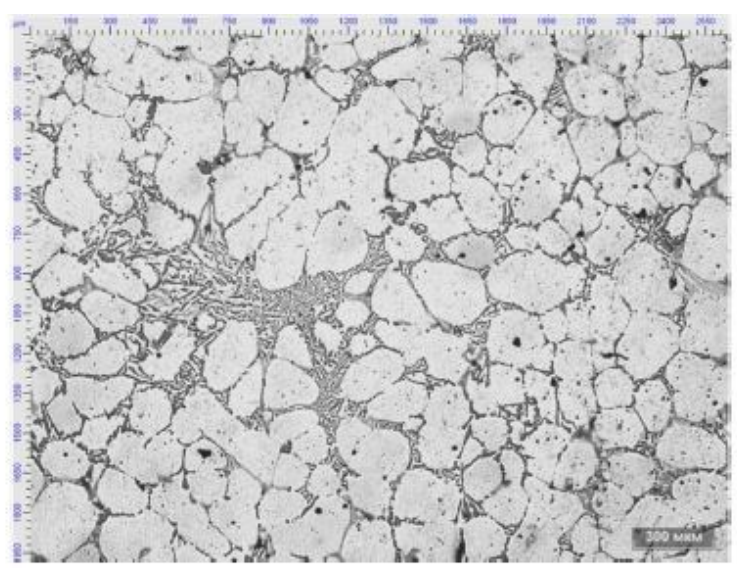

b

Figure 6. AK7 alloy structure: a - UT within $607-600^{\circ} \mathrm{C}, 6 \mathrm{~min}$.; $\mathrm{b}-\mathrm{UT}$ at $600^{\circ} \mathrm{C}, 6 \mathrm{~min}$. X20, etching

As is seen, UT at below liquidus temperatures, i.e., in a liquid-solid state, contributed to a rather high degree of the dendrite structure degeneration.

When analyzing the pattern of temperatures (Figure 5), one ought to pay attention to long-term temperature control (Temperatures $3-4$ ), when exposed to UT. It is fair to assume that in alloys having a crystallization interval, there is a characteristic temperature at which energy introduced during UT is taken by the melt to the fullest extent possible and, therefore, the UT at this temperature can be the most effective one.

Experiment 3. The goal was to study impact of duration of the starting charge heating to solid-liquid state, temperature-time treatment and UT upon the dendrite structure evolution.

Weighted amount of AK7 alloy, 3,5 kg, was charged into a steel crucible, heated to $590^{\circ} \mathrm{C}$, as well as the furnace, within 120 minutes. Upon reaching $550^{\circ} \mathrm{C}$ one started to supply argon. The further experimental procedure is presented in Figure 7.

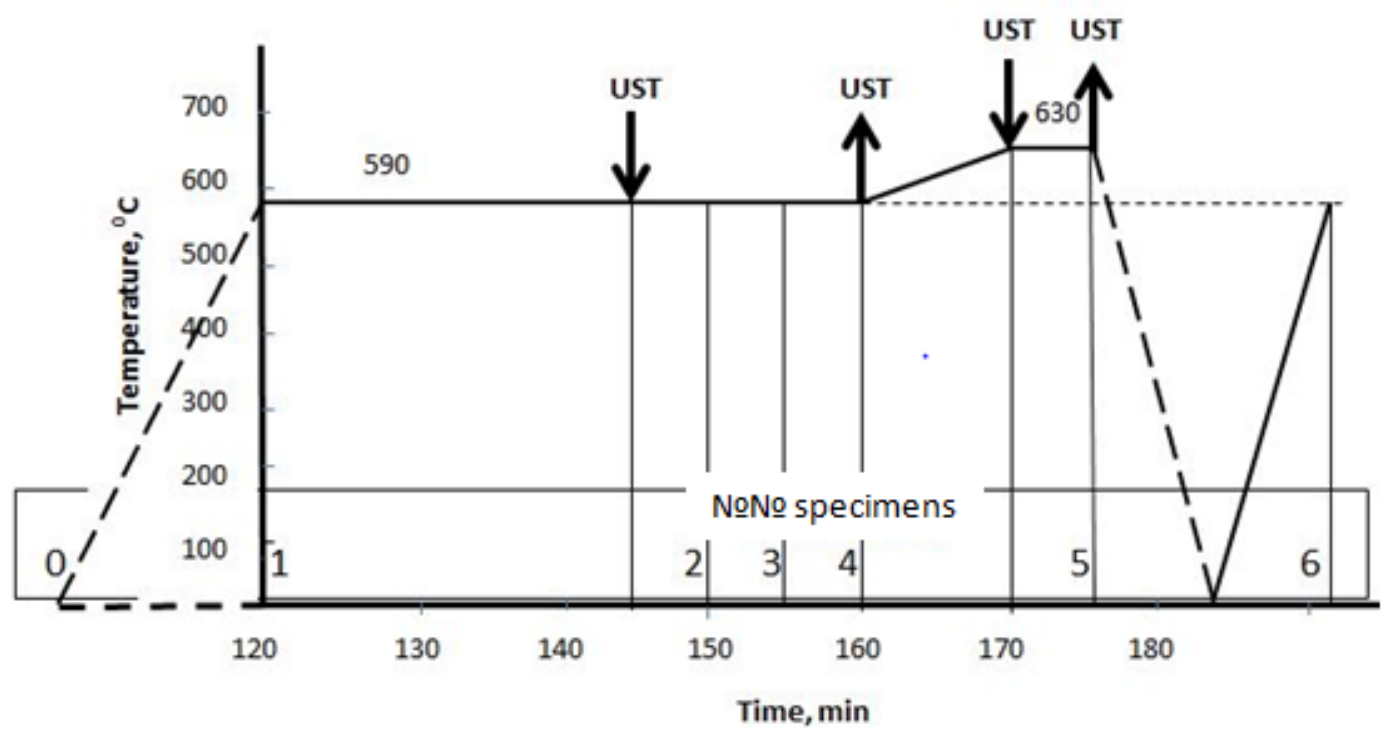

Figure 7. Experiment 3 diagram: - UT beginning (UST), - UT ending (UST)

The following reagent was used for etching operation: $5 \% \mathrm{HF}+10 \% \mathrm{H} 2 \mathrm{SO} 4$, water rest. Microstructures of corresponding samples are presented in Figures 8 and 9. 


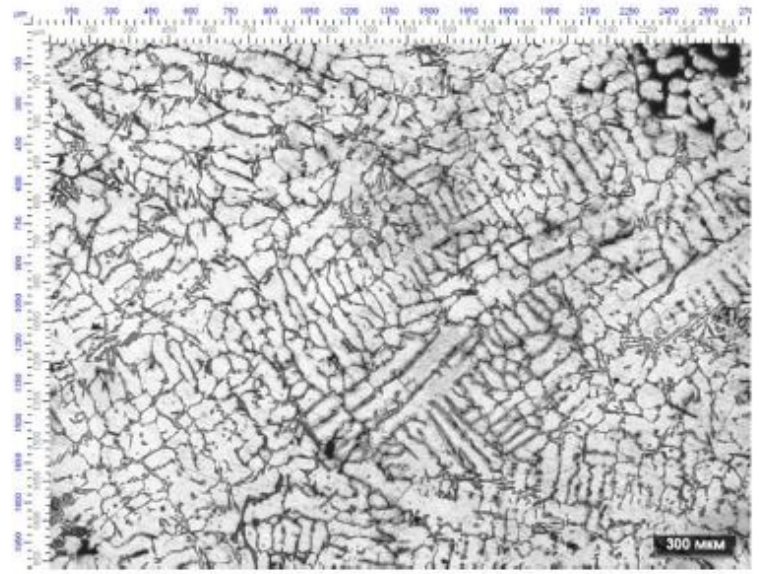

a

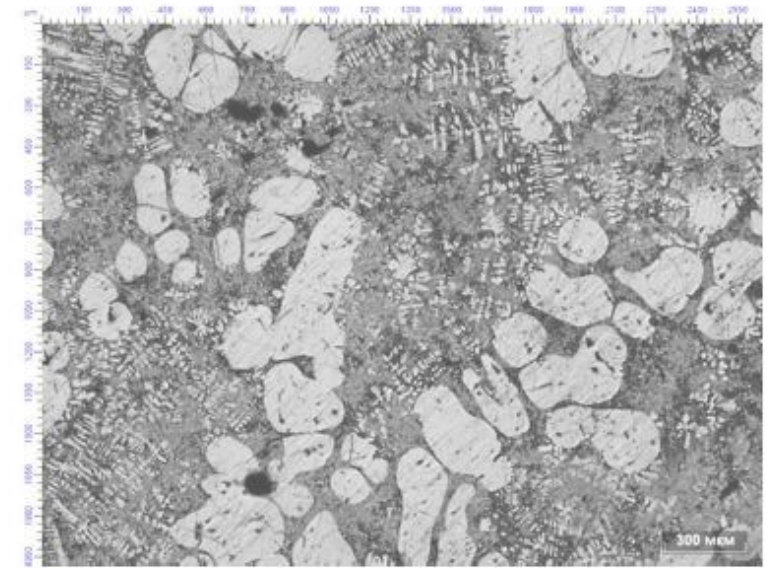

b

Figure 8. AK7 alloy structure: $\mathrm{a}$ - charge; $\mathrm{b}$ - heating up to $590^{\circ} \mathrm{C}, 120 \mathrm{~min}$. X20, etching

When comparing microstructures of charge (Sample 0, Figure 8, a) and Sample 1 (Figure 8, b), it may be observed that slow heating led to partial transformation of starting dendrites of solid-state solution to large inclusions, round-shaped, with typically small-sized dendrites present. Apparently, during slow heating within $564^{\circ} \mathrm{C}-590^{\circ} \mathrm{C}$ range, fragmentation and partial melting of dendritic network took place, enlargement and compaction (degeneration) of the dendrite structure due to coalescence of sub-grains and prior coagulation of fragments of starting dendrites. Upon dissolving of a part of dendrites in the liquid state composition, aluminium content increased, that of silica decreased, correspondingly, the liquid state composition became hypoeutectic. Secondary smallsized dendrites of the solid-state solution formed in Sample 1 during heat treatment.

Long-term keeping (25 minutes) and UT of the alloy, heated to temperature of the liquid-solid state, within 5 minutes (Sample 2), could hardly have impact upon the shape of inclusions. Upon UT prolongation to 10 (Sample 3) and 15 (Sample 4) minutes, no significant changes were observed.

Heating up to $630^{\circ} \mathrm{C}$ und UT within 5 minutes (Sample 5, Figure 9, b) of alloy, previously exposed to UT within 15 minutes at $590^{\circ} \mathrm{C}$ (Sample 4, Figure 9, a) led to fragmentation of the dendrite structure, enlargement of the degenerated dendrites area and their rounding.

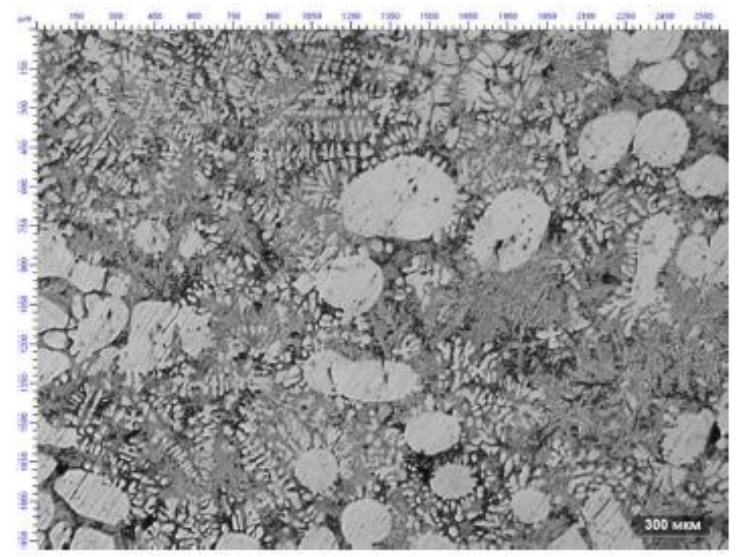

a

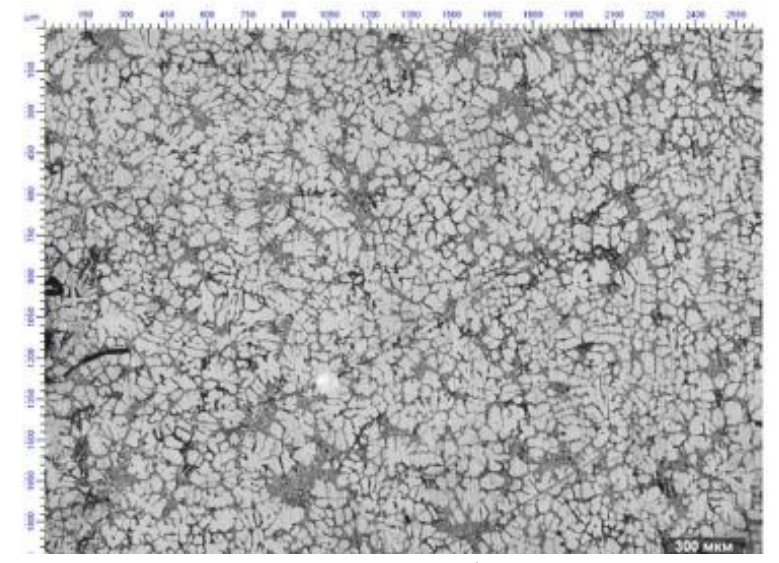

$\mathrm{b}$

Figure 9. AK7 alloy structure: a - keeping at $590^{\circ} \mathrm{C}$ within $25 \mathrm{~min}$. + UT $15 \mathrm{~min}$. (Sample 4); b-heating up to $630^{\circ} \mathrm{C}+\mathrm{UT} 5$ min. (Sample 5). X20, etching

The study of the structure of Sample 6 (Figure 10) shows as follows: repeated heating of the alloy of the degenerated dendrite structure leads to partial recovery of the starting dendrite structure. It can be expected that the use of such a material as charge for further UT of the alloy makes it possible to reduce the UT time for formation of a thixotropic structure within the alloy. 


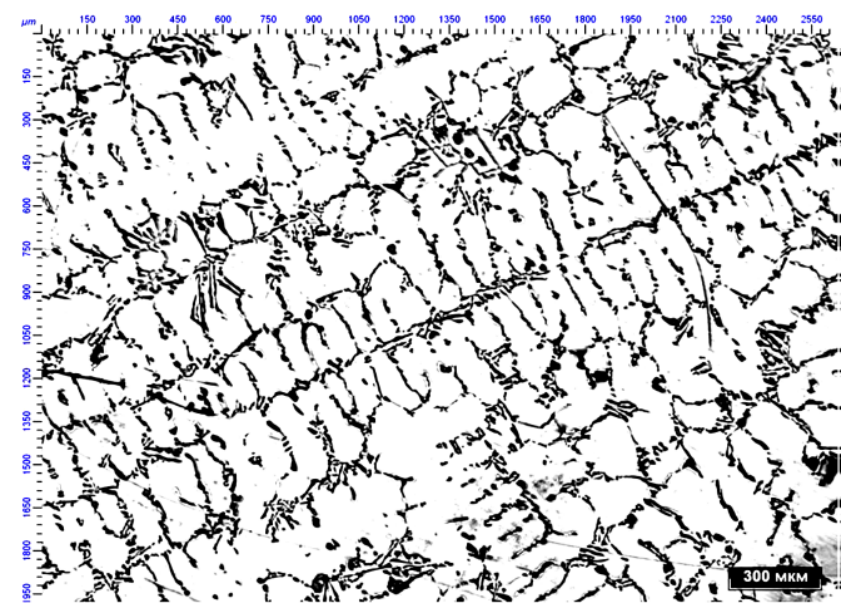

Figure 10. AK7 alloy structure with dendrite structure degenerated (Sample 5) upon cooling and repeated heating up to $590^{\circ} \mathrm{C}$ (Sample 6). X20, etching

Analyzing results of Experiment 3, it may be noted that:

- Efficiency of UT impact upon a degree of the dendrite structure degeneration depends on the temperature interval and processing time. The UT impact upon the dendrite structure is the most effective, with the alloy in the solid-liquid state.

- UT impact upon the evolution of the dendrite structure is more efficient than long-term heating of charge up to its melting point and long-term keeping of the molten mass under isothermal conditions.

- UT of the alloy being in the solid-liquid state, with charge being partially heated, cannot guarantee formation of the dendrite structure, but can presumably accelerate that process upon slight overheating of the alloy (above liquidus temperature) and further short-term UT in the liquid-solid state.

2. Impact of magneto-hydrodynamic action (MHD) and plasma treatment (PT) upon AK7 alloy structure $[8,9]$.

When using the thixo-casting technology, the first stage must be to produce the mass, using semicontinuous casting technique, with regular distribution of elements in the ingot cross-section and partial or complete degeneration of the dendrite structure of the solid-state solution.

A research was conducted to examine the MHD-stirring impact upon silicon and magnesium sweating, when using a ring-type MHD device enabling to stir the alloy within a crystallizer, vertically and horizontally. It has been established that alloy stirring, both vertically and horizontally, removes silicon and magnesium sweating in the ingot cross-section (Figure 11), which provides for a high degree of the starting dendrite structure degeneration.
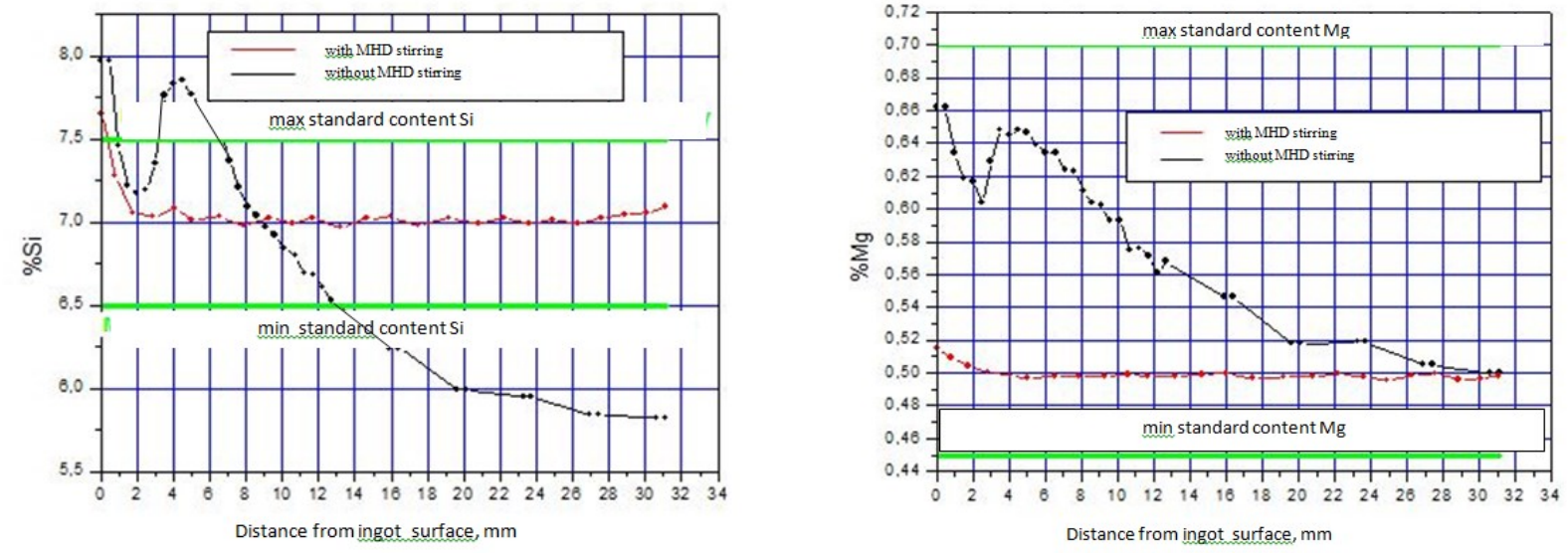

Figure 11. MHD-mixing impact upon distribution of silicon (a) and magnesium (b) in A356 alloy ingot. 
During research of a possibility to produce aluminium-matrix composites using plasma synthesis, developed at the All-Union Aluminium-Magnesium Institute (Saint-Petersburg), one used a laboratory facility, comprising of a resistance furnace to melt Ak7 alloy, as well as a plasma synthesis facility to include a plasmatron and MHD-mixer (Figure 12).

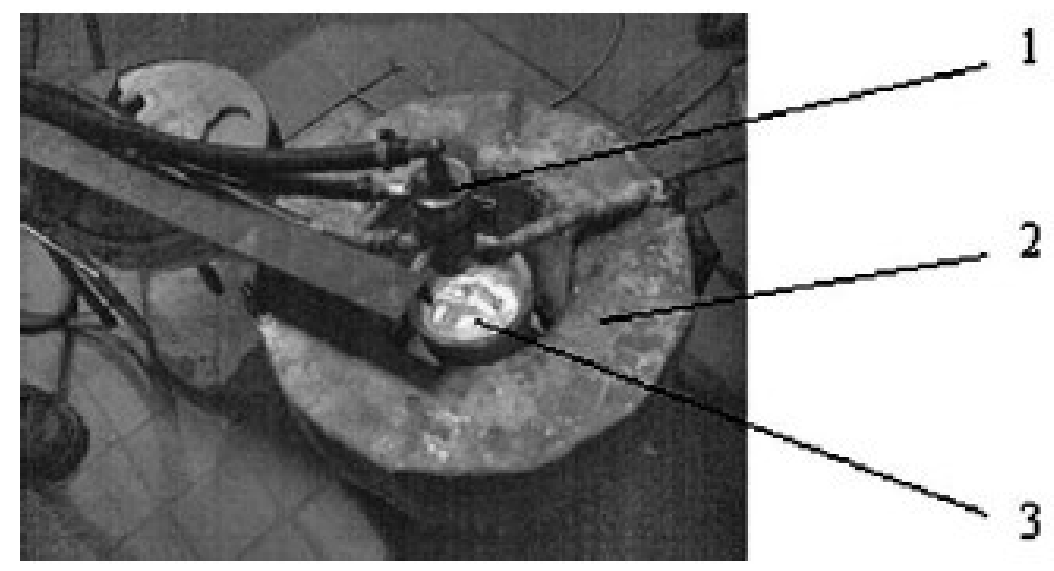

Figure 12. Installation of plasma synthesis: 1 - plasmatron, 2 - MHD stirring, 3 - crucible with melt

To introduce $\mathrm{SiC}$ and $\mathrm{A} 12 \mathrm{O} 3$ nanosized powders (less than $100 \mathrm{~nm}$ ) into the melt using the plasmatron, the powders were, during mechanical alloying within a high-energy mill (attrition mill), stirred with micrometric (50 - 80 micron) copper or copper-nickel powders, which led to introduction of nanosized powders of high-melting compounds into a body of micrometric carrying powders. Nano-structured powder composites (NPC) prepared were introduced, using the plasmatron, under the surface of melt with simultaneous MHD-mixing and argon supplying to protect the melt surface within a graphite-fireclay crucible.

The starting alloy A357 (mass. \%) composition: 7,5Si, 0,35 Fe, 0,45 Mg, 0,02 Mn, 0,06 Ni, 0,03 $\mathrm{Cu}, 0,08 \mathrm{Zn}, \mathrm{Al}$ res. The starting alloy $\mathrm{A} 357$ properties in the cast state: $\mathrm{Rm}=155 \mathrm{MPa}, \mathrm{A}=3,5 \%$. In the first series of experiments the alloy A357 $(2 \mathrm{~kg})$ was heated in a resistance furnace up to $800^{\circ} \mathrm{C}$ and there was mixed and removed the heated universal flux was, the crucible was brought to the electromagnetic stirring, in the process of mixing using a plasma facility there was introduced $5 \%$ nanostructured powder composite $(62,5 \% \mathrm{Cu}+28,1 \% \mathrm{Ni}+3,1 \% \mathrm{SiC})$. The introducing durability (work of plasmatron and mixer) was $50 \ldots 60 \mathrm{~s}$, the metal temperature in the process of the material introducing was reduced to $720 \ldots 750^{\circ} \mathrm{C}$, after which in the chill mold there were poured samples with of diameter of $12 \mathrm{~mm}$ and $100 \mathrm{~mm}$ of length. The design assimilation of the material was $94 \%$, before heat treatment at normal temperature $\mathrm{Rm}=280 \mathrm{MPa}, \mathrm{A}=3,5 \%$. After T6 at normal temperature $\mathrm{Rm}=390 \mathrm{MPa}, \mathrm{A}=7,5 \%$, at $350^{\circ} \mathrm{C}-\mathrm{Rm}=160 \mathrm{MPa}, \mathrm{A}=11 \%$.

In the second series of experiments the conditions were identical to the first one, however, in the melt using a plasma facility there was introduced 5\% nanostructures powder composite material containing 95,5\% $\mathrm{Cu}+4,5 \% \mathrm{~A} 12 \mathrm{O} 3$. The design assimilation of this material made $92 \%$, before heat treatment at normal temperature $\mathrm{Rm}=290 \mathrm{MPa}, \mathrm{A}=4,5 \%$. After $\mathrm{T} 6$ at normal temperature $\mathrm{Rm}=405 \mathrm{MPa}, \mathrm{A}=8,5 \%$, at $350^{\circ} \mathrm{C}-\mathrm{Rm}=165 \mathrm{MPa}, \mathrm{A}=12,5 \%$.

Metallographic research confirmed presence of nanosized $\mathrm{SiC}$ inclusions within composites (Figure 13) and feasibility of using the plasma synthesis with MHD-stirring of the alloy to produce aluminium-matrix nanocomposites. 


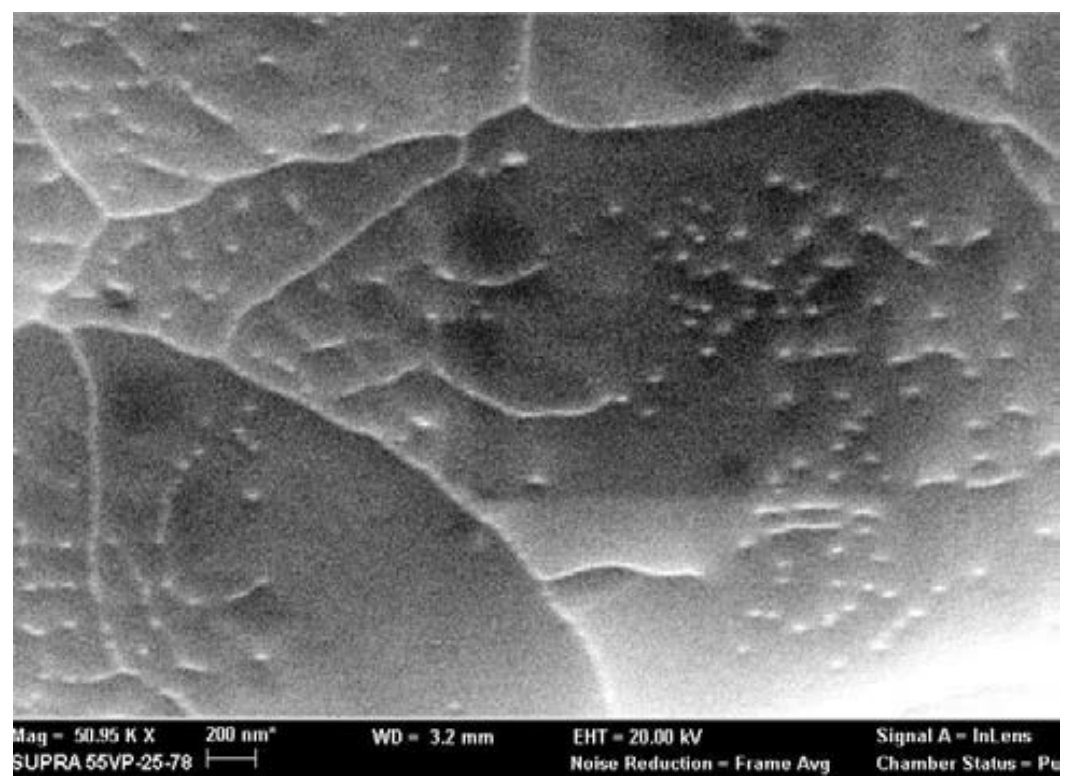

Figure 13. A357( $\mathrm{SiC})$ composite structure. Etched 50\% H.SO.

\section{References}

[1]. T.A. Chernishova, I.E. Kalashnikov, A.V. Samohin, N.V. Alexeev, L.K. Bolotova, L.I. Kobeleva. Study of modifying influence of nanopartical additives produced by plasma-chemical synthesis of structure of cast aluminium matrix composite materials www.nanoru.ru| Vol. 4 | №78 ,2 009 | Rossiyskie Nanotechnologii, pp.149-153.

[2]. Koch C. C. Nano structured materials: processing, properties, and potential applications', 423526; 2002, Norwich, NY, Noyes Publications.

[3]. G. A. Kosnikov, O. L. Figovsky, A. S. Eldarkhanov/ Liquid Phase Production Technologies of Metal Matrix Composites (Review) // International Letters of Chemistry, Physics and Astronomy 6 (2014) 69-77.

[4]. Eldarkhanov A.S., Efimov B.A., Nuradinov A.C.. Cast product formation processes and their modelling, M., Mashinostryeniye. 2001, 208p.

[5]. V.A. Efimov, A.S. Eldarkhanov. Technologies of modern metallurgy M., Noviye tekhnologii, 2004. 784p.

[6]. V.O. Abramov, O.V. Abramov, V.V. Artemev, O.M. Gradov, N.P. Kolomeets, V.M. Prikhodko, A.S. Eldarkhanov. High-power ultrasound in metallurgy and mechanical engineering. M., Yanus-K, 2006. 688p.

[7]. G.A. Kosnikov, O.X. Figovsky, A. S. Eldarkhanov, V.H. Mezhidov, S. S. Yusupov. Possibilities of use of high-power ultrasound for alloy treatment in the production of nanostructured alumomatrix composites //Journal "Scientific Israel - Technological Advantages" vol.15, M2 (Letters), 2013, 93-96

[8]. G.A.Kosnikov, S.S.Kolesov. Influence of MHD-mixing on the structure of alloys, treated in solid-liquid state. Works of VII Congress of Russian foundrymen. Novosibirsk, 2005.Vol. 1, pp. 298-303.

[9]. G.A. Kosnikov, V.A. Baranov, S.Y. Petrovich, A.V. Kalmykov. Cast nanostructured composite alloys. Liteinoye proizvodstvo, No. 2, 2012. pp. 4-9. 